\title{
Acolhimento aos usuários do serviço de Odontologia de uma universidade pública
}

\author{
Patrícia Elizabeth Souza Matos*; Haroldo José Mendes*; Mateus Lessa Santana**
}

* Doutor em Ciências Odontológicas Aplicadas, área de concentração Odontologia em Saúde Coletiva, Professor Adjunto do curso de Odontologia da Universidade Estadual do Sudoeste da Bahia.

** Estudante do curso de Odontologia da Universidade Estadual do Sudoeste da Bahia.

Recebido em 11/07/2016. Aprovado em 10/10/2016.

\begin{abstract}
RESUMO
O curso de Odontologia da Universidade Estadual do Sudoeste da Bahia desenvolve atividades clínicas no Módulo de Odontologia, um espaço de ensino e aprendizagem que oferta atendimento odontológico para população do município de Jequié/BA. Este estudo objetivou fazer uma análise do processo de acolhimento aos usuários deste serviço, de maneira a identificar como se dá a porta de entrada, e a percepção dos usuários sobre o atendimento prestado. Trata-se de um estudo essencialmente qualitativo, onde foi utilizado um roteiro semiestruturado para entrevistar 45 usuários. Os achados do material empírico foram divididos em 3 temas foco: Acesso ao atendimento odontológico, relação com professores e alunos durante o atendimento odontológico, e opinião sobre o serviço odontológico prestado. Os usuários consideraram terem sido bem recebidos, mas apontaram dificuldades relativas ao início do tratamento. No que tange à relação entre as partes durante o atendimento, os usuários ressaltaram pontos que indicam a existência de uma prática humanizada de atenção à saúde bucal. A análise dos depoimentos identificou falhas no processo de acolhimento aos usuários, o que leva a reflexões em torno da organização da "porta de entrada" e da continuidade do tratamento até sua resolução. Tais achados se constituem em valorosas informações para embasar discussões em torno da dinâmica de funcionamento do setor e numa formação dos graduandos de Odontologia que considere a importância de efetivação de todo o processo de acolhimento.
\end{abstract}

Descritores: Acolhimento. Usuário. Humanização da Assistência.

\section{INTRODUÇÃO}

Considerando o contexto do Sistema Único de Saúde (SUS), foi percebida a necessidade de aprimorar a forma de sintetizar e operar as ações de saúde, tendo como ênfase a defesa da vida dos direitos sociais plenos, além de poder dar resolubilidade aos problemas encontrados na rotina de trabalho e norteados para a autonomia dos usuários e comunidades. Diante disso, surgiu em meados da década de 90, o "acolhimento", que se constitui uma ferramenta de suma importância para gerar mudanças na forma de organização dos serviços de saúde, integralidade de acesso, além de qualificar o vínculo entre profissionais e usuários ${ }^{1}$.

$\mathrm{O}$ processo de acolhimento busca um novo 
significado na relação do profissional com o usuário, considerando-o em toda a sua subjetividade de maneira a incluí-lo em um contexto cultural e socioambiental ${ }^{2}$. Ao inserir o acolhimento no modelo de atenção à saúde, alguns fatores devem ser modificados para facilitar o acesso, tais como, processo de trabalho em saúde e a porta de entrada da unidade de saúde ${ }^{3}$.

O acolhimento torna-se uma alternativa capaz de modificar alguns desígnios como, superar o modelo médico-centrado para usuáriocentrado, qualificar o vínculo trabalhadorusuário por meios de parâmetros humanitários e de cidadania, e sugerir escolhas de solução da demanda que procuram o serviço ${ }^{4}$.

Com a realização da XII Conferência Nacional em Saúde em (CNS), que teve como debate a universalidade do acesso ao SUS, da valorização dos usuários e dos trabalhadores na participação e na gestão do sistema, surgiu, em 2003, a Política Nacional de Humanização da Atenção e Gestão do SUS - Humaniza SUS $(\mathrm{PNH})^{5}$. O "Humaniza SUS", sustenta-se em tecnologias relacionais para produzir saúde considerando novas formas de pensar, perceber, sentir, escutar e reconhecer a centralidade dos processos de subjetividade de todos os sujeitos envolvidos na produção da mesma. Neste aspecto, a humanização pode ser entendida como uma forma de acolhimento, ou seja, uma maneira mais humana de garantir o acesso dos usuários aos serviços de saúde ${ }^{6}$.

Considerado como uma tecnologia leve por Merhy, Enocko ${ }^{7}$, o acolhimento direciona-se para o estabelecimento de táticas de atendimento, que envolve tanto trabalhadores como gestores e usuários. Portanto, as penúrias sentidas pelos últimos poderão ser trabalhadas pelos profissionais com a finalidade de proporcionar a resolubilidade para as exigências de saúde.

Entretanto, apesar dos grandes avanços na área odontológica no que concerne a técnica para sua efetiva realização, ainda é deficiente a ideia de que o serviço odontológico seja muito mais do que somente recuperar a função e a estética do paciente. Sendo assim, o acolhimento deve ser considerado como parte primordial do atendimento odontológico, e por isso mesmo deve ser trabalhado durante a formação profissional dos acadêmicos de Odontologia, independente da sua futura inserção no mercado de trabalho, seja no setor público ou privado ${ }^{8}$.

Destarte, este estudo possibilitou uma reflexão sobre as ações de acolhimento ao usuário no Módulo de Odontologia da Universidade Estadual do Sudoeste da Bahia (UESB), uma vez que os resultados encontrados podem auxiliar na discussão e desenvolvimento de medidas voltadas para a avaliação e reorganização do processo de trabalho com a sensibilidade de toda equipe a qual almeja um trabalho interdisciplinar consistente e mais eficiente, além de contribuir na formação dos futuros cirurgiões-dentistas ${ }^{3}$.

Corroborando com tais conhecimentos, buscou-se neste estudo analisar o processo de acolhimento aos usuários no Módulo de Odontologia da UESB, de maneira a identificar como se dá a porta de entrada ao serviço e a percepção dos usuários sobre o atendimento prestado.

\section{METODOLOGIA}

Trata-se de um estudo descritivo do tipo transversal, essencialmente qualitativo. A população estudada foi composta por 45 indivíduos, usuários do serviço de assistência odontológica prestado na UESB. Foram selecionados, de forma aleatória, três indivíduos que estivessem sob atendimento clínico odontológico em cada uma das 15 disciplinas clínicas que compõem a matriz curricular do curso. Nas disciplinas de Clínica 
Odontopediátrica, na impossibilidade das crianças participarem das entrevistas, estas foram representadas pelos acompanhantes ou responsáveis legais.

O curso de Odontologia da UESB funciona desde 2004 no campus universitário de Jequié/BA e tem a maior parte de suas atividades desenvolvidas no Módulo de Odontologia, um espaço composto basicamente por salas de aula, laboratórios, clínicas e área de recepção. O Módulo de Odontologia constitui um ambiente de estudo e aprendizado dos acadêmicos do curso, onde através da ação conjunta entre alunos e professores são prestados serviços odontológicos à população. Nesse aspecto, torna-se indispensável que seja não apenas um local que ofereça assistência odontológica, mas também um lugar de escuta, orientação, encaminhamento e acompanhamento dos indivíduos, almejando um processo de atendimento mais humanizado ${ }^{8}$.

O estudo foi iniciado após aprovação do projeto pelo Comitê de Ética e Pesquisa da UESB (CAAE 45079215.4.0000.0055), de acordo com as recomendações contidas na resolução 466/2012 do Conselho Nacional de Saúde ${ }^{9}$.

O método escolhido para coleta de informações foi a entrevista gravada, seguindo um roteiro semiestruturado de perguntas, de maneira a coletar depoimentos que permitissem o acesso a dados da realidade que representassem a percepção dos usuários acerca do acolhimento durante $\mathrm{o}$ período em que procurou o atendimento odontológico. Tal roteiro foi testado em sua funcionalidade, numa situação piloto, no ambiente de uma Unidade de Saúde do município.

A opção pela entrevista se fez por se tratar de uma técnica de coleta de informações, que oferece a possibilidade da fala ser reveladora de condições estruturais, de sistemas de valores, normas e símbolos e, ao mesmo tempo, tem a magia de transmitir, através de um porta-voz, as representações de grupos determinados, em condições históricas, socioeconômicas e culturais específicas.

As entrevistas foram realizadas enquanto os usuários aguardavam o atendimento odontológico. Antes do início da gravação o pesquisador esclareceu o procedimento de coleta de informações, os objetivos do estudo, e diante da afirmativa em responder às perguntas, os entrevistados leram e assinaram o Termo de Consentimento Livre e Esclarecido, no qual concordavam em participar como voluntários (as) na pesquisa.

O tratamento do material colhido através da abordagem qualitativa foi feito de acordo com o método de análise de conteúdo baseado em Minayo $^{10}$, e que segundo Bardin ${ }^{11}$, pode ser definido como: "Um conjunto de técnicas de comunicação visando obter, por procedimentos sistemáticos e objetivos de descrição do conteúdo das mensagens, indicadores (quantitativos ou não) que permitam a inferência de conhecimentos relativos às condições de produção/recepção destas mensagens"

$\mathrm{O}$ processo de análise de dados seguiu alguns passos sugeridos por Minayo ${ }^{10}$. Primeiramente foi feita a transcrição fiel das entrevistas gravadas; seguida por leitura exaustiva e "flutuante" dos textos transcritos das entrevistas; depois foram feitos recortes dos textos das entrevistas que representassem a ideia central sobre o tema foco e estes foram agrupados em núcleos de sentido.

Numa segunda etapa foi realizada nova leitura a partir dos núcleos de sentido, fazendose uma filtragem dos conteúdos mais relevantes relacionados ao objeto do estudo, às questões orientadoras e aos pressupostos teóricos.

Desta forma, foi possível investigar a existência de confronto de ideias entre as diferentes representações, dando seguimento a análise final dos dados, realizando um 
entrelaçamento entre a teoria e os dados obtidos através das entrevistas.

\section{RESULTADOS}

Os 45 usuários participantes do estudo responderam a todas as questões do roteiro durante a entrevista.

A análise do material empírico apreendido na coleta de dados foi realizada com base na proposta de análise de conteúdo, organizando-os por "tema foco", com recortes dos textos das entrevistas que representassem a mesma ideia central sobre o tema foco.

O quadro 1 apresenta a maneira como acontece o primeiro contato físico do usuário com o serviço de odontologia da UESB, esse contato se dá ainda na recepção, na sala de espera do Módulo de Odontologia, e constitui um importante passo para a organização do processo de trabalho.

No quadro 2 foram pontuadas várias questões que retratam a relação entre profissionais de saúde, ou seja, professores e alunos de odontologia, e usuários; num ambiente de prestação de serviço de saúde que também é um cenário de ensino-aprendizagem.

O quadro 3 apresenta a percepção do usuário sobre o serviço de saúde prestado na unidade de ensino superior.

\section{DISCUSSÃO}

Um dos primeiros passos para organização de um serviço de saúde é investigar os caminhos percorridos pelos sujeitos até a chegada ao sistema de saúde ${ }^{12}$.

Nesta pesquisa, os usuários consideraram terem sido bem recebidos, houve uma concordância geral nesse quesito. Contudo existem algumas dificuldades a serem sanadas com relação ao acesso ao atendimento odontológico.

"Fui recebida bem, só tomei um chá de cadeira aguardando ser chamada."

Quadro 1. Acesso ao atendimento odontológico.

\begin{tabular}{|l|l|}
\hline \multicolumn{2}{|l|}{ TEMA FOCO: ACESSO AO ATENDIMENTO ODONTOLÓGICO } \\
\hline IDEIAS CENTRAIS & RECORTES DOS TEXTOS DAS ENTREVISTAS \\
\hline Sem dificuldades & $\begin{array}{l}\text { "Fui bem recebida. Cheguei aqui me perguntaram se eu já tinha } \\
\text { ficha, aí falei que não, e eles fizeram e hoje já me chamou. Não } \\
\text { tive dificuldade até achei rápido (risadas)." }\end{array}$ \\
\hline $\begin{array}{l}\text { Longo tempo de espera } \\
\text { entre o agendamento e o } \\
\text { atendimento }\end{array}$ & $\begin{array}{l}\text { "Me receberam bem. Não tive dificuldade em maito demorado para ser chamado." } \\
\text { matendimento, }\end{array}$ \\
\hline $\begin{array}{l}\text { Falta de } \\
\text { uniformidade na } \\
\text { informação }\end{array}$ & $\begin{array}{l}\text { "Na primeira vez que eu vim eles falaram que não tinha vaga e que só } \\
\text { não pode esperar né, aí tem que pagar pra rancar o dente... mas } \\
\text { depois disso os alunos e professores passaram em casa e me falaram } \\
\text { para eu vim até aqui." }\end{array}$ \\
\hline
\end{tabular}


Quadro 2. Relação com professores e alunos durante o atendimento odontológico

\begin{tabular}{|c|c|}
\hline \multicolumn{2}{|c|}{ TEMA FOCO: RELAÇÃO COM PROFESSORES E ALUNOS DURANTE O ATENDIMENTO ODONTOLÓGICO } \\
\hline IDEIAS CENTRAIS & RECORTES DOS TEXTOS DE ENTREVISTAS \\
\hline $\begin{array}{l}\text { O diálogo como } \\
\text { elemento fundamental } \\
\text { do atendimento }\end{array}$ & $\begin{array}{l}\text { "Fui recebida maravilhosamente bem. Eles fizeram várias perguntas sobre a } \\
\text { criança... conversam, escutam, explicam o tratamento, aquela coisa toda." } \\
\text { "Rapaz, aí foi legal mesmo! Conversaram me fizeram um monte de perguntas. } \\
\text { Eu acho essa conversa legal porque tira até aquele susto que você tem né, tira } \\
\text { aquela máscara... se você conversa acaba tirando o medo, e é melhor do que } \\
\text { você chegar ver aquele motorzinho, porque você fica mais tenso." } \\
\text { "A comunicaçâo deles com a gente melhora o atendimento, se ficar só focado } \\
\text { no trabalho a gente não fica à vontade em falar o que tá sentindo no dente. Essa } \\
\text { forma de conversar acaba beneficiando o tratamento... é como se conhecesse } \\
\text { aquela pessoa há muito tempo." }\end{array}$ \\
\hline $\begin{array}{l}\text { O valor de ser tratado } \\
\text { pelo "Nome" durante } \\
\text { o atendimento }\end{array}$ & $\begin{array}{l}\text { "Toda vez que eu chegava, eu era bem recebido e ela já vinha e falava: Oh seu } \\
\text { Valdo, aguarda um pouquinho que eu vou arrumar as coisas para dá início ao } \\
\text { tratamento." }\end{array}$ \\
\hline $\begin{array}{l}\text { O estabelecimento de } \\
\text { uma relação de } \\
\text { confiança }\end{array}$ & $\begin{array}{l}\text { "[...] falou o que ia fazer e tudo isso é bom porque passa mais confiança pra } \\
\text { gente. Eu mesmo não gostava de dentista porque chegava lá e eles não falavam } \\
\text { o que tava acontecendo, e aqui não, os alunos explicam tudo o que vai fazer. } \\
\text { Isso aproxima o profissional do paciente" }\end{array}$ \\
\hline $\begin{array}{l}\text { A importância da } \\
\text { relação } \\
\text { professor/aluno diante } \\
\text { dos pacientes }\end{array}$ & $\begin{array}{l}\text { "Assim né, as meninas foram excelentes... fizeram um trabalho maravilhoso, } \\
\text { mas só teve um professor que me deixou meio que com medo de voltar aqui } \\
\text { outra vez, porém as meninas me explicaram tudo, e isso me deixou mais } \\
\text { tranquila, apesar delas estarem começando..." }\end{array}$ \\
\hline
\end{tabular}

Quadro 3. Opinião sobre o serviço odontológico prestado.

\begin{tabular}{|c|c|}
\hline \multicolumn{2}{|c|}{ TEMA FOCO: OPINIÃO SOBRE O SERVIÇO ODONTOLÓGICO PRESTADO } \\
\hline IDEIAS CENTRAIS & RECORTES DOS TEXTOS DE ENTREVISTAS \\
\hline $\begin{array}{l}\text { Elogios ao } \\
\text { atendimento }\end{array}$ & $\begin{array}{l}\text { "Eu achei bom. Uma oportunidade que em outras unidades não vamos } \\
\text { encontrar, bom em tudo, na atenção, em tudo mesmo... porque nos postos de } \\
\text { saúde não tá tendo não." } \\
\text { "Fui bem recebido. Alunos e professores são pontuais. O atendimento em si já } \\
\text { é bom. Existe uma escuta, diálogo entre alunos e pacientes". }\end{array}$ \\
\hline $\begin{array}{l}\text { Elogios ao } \\
\text { atendimento com } \\
\text { ressalvas }\end{array}$ & $\begin{array}{l}\text { "Eu sou bem suspeito pelo fato de admirar mesmo o trabalho, mas acho } \\
\text { que..." } \\
\text { "O tratamento aqui é excelente, mas queria sugerir assim que..." }\end{array}$ \\
\hline $\begin{array}{l}\text { Críticas ao } \\
\text { descumprimento do } \\
\text { horário agendado para } \\
\text { atendimento }\end{array}$ & $\begin{array}{l}\text { "Assim, uma coisa meio que incomoda aqui é o horário, hoje mesmo me marcou } \\
\text { para 8:30 e até agora nada... estou aqui plantada desde 8:00. Quando cheguei } \\
\text { aqui o estudante veio me falar que tinha uma pessoa que ia ser atendida antes } \\
\text { de mim. Então não me marcava neste horário!..." } \\
\text { “... deveria organizar mais os horários porque marcam para um horário e vão } \\
\text { atender em outro." } \\
\text { "... o fato dos professores demorarem de chegar." }\end{array}$ \\
\hline $\begin{array}{l}\text { Interrupções e falta de } \\
\text { continuidade do } \\
\text { tratamento } \\
\text { odontológico }\end{array}$ & $\begin{array}{l}\text { "A única parte ruim daqui é que às vezes tem paralisações, tem greves e aí a } \\
\text { gente fica com o tratamento no meio do caminho...” } \\
\text { "... teve que interromper o tratamento devido ao recesso, aí quando voltou teve } \\
\text { que começar tudo de novo, e isso eu acho um ponto negativo porque acaba } \\
\text { demorando muito, eu mesmo tem mais de } 3 \text { anos que estou aqui!”" }\end{array}$ \\
\hline
\end{tabular}


De acordo com relatos, o primeiro contato, ou seja, a realização do cadastro não se constitui um problema, contudo o período de espera pelo início do tratamento odontológico é longo, e a avaliação da real necessidade imediata do paciente não é realizada.

"Dificuldade em marcar não, porém demorou muito para chamar, esperei de 6 a 7 meses mais ou menos e isso acaba atrapalhando né, porque se a gente está precisando do tratamento e não temos condições de pagar, e ficar esperando... e se a criança ou adulto tá sentido dor, mas fazer o que né?! Esperar!"

A deliberação em torno da necessidade de consulta imediata depende da avaliação de um profissional, e esta etapa já se constitui como parte do acolhimento ${ }^{12}$. Quando o usuário procura o serviço odontológico de uma clínicaescola é imprescindível que haja uma organização desta "porta de entrada", e que esta não se restrinja apenas ao agendamento, mas que tenha uma classificação de risco dos pacientes. O termo acolhimento é rotineiramente concebido na prática como espaço para "recepção" ou "triagem" de pacientes ${ }^{13}$.

Entretanto, existe diferença entre triagem e acolhimento, pois a primeira se refere a uma filtragem dos usuários em relação aos procedimentos oferecidos sem considerar as distintas necessidades destes, e o acolhimento deve ser inserido em todos os locais e momentos do serviço de saúde não constituindo parte do processo de triagem ${ }^{3}$. $\mathrm{O}$ acolhimento ainda pode ser considerado "formal" o qual consiste no atendimento agendado, individualizado e com espaços e metodologias definidas, e "informal" que não requer nem horário nem local definido, podendo o usuário ser atendido pelo profissional no momento em que estiver disponível ${ }^{13}$.

Ainda considerando a porta de entrada do usuário ao atendimento odontológico, foram observadas situações bem distintas, onde de um lado o usuário não identificou qualquer tipo de dificuldade em acessar o serviço odontológico da universidade, achando o processo entre $\mathrm{o}$ "agendamento" e o "atendimento" até rápido; e por outro lado foi relatada uma situação explícita de falta de uniformidade nas informações repassadas ao usuário.

"Na primeira vez que eu vim aqui não podia ser atendido. Aí vim aqui de tarde e me pediram pra vir outro dia. No dia seguinte cheguei aqui 4 da manhã aí fiquei esperando, aí o segurança ficou com pena de mim e pediu para um professor e aluno me atender. Então eu consegui entrar dessa forma com muita insistência. "

Diante do exposto, fica configurada uma falha no processo de acolhimento, uma vez que este se inicia desde a forma de entrada até momento de saída dos usuários dos serviços se caracterizando parte essencial para que exista um bom atendimento e concomitantemente um acolhimento adequado ${ }^{14}$.

É fundamental entender o acesso como a "porta de entrada", o local de acolhimento do usuário ao buscar os serviços de saúde, sendo, posteriormente, seguido até ao ponto onde a resolução da necessidade do usuário é efetivada ${ }^{15}$. Sendo assim, pode-se afirmar que o acesso ao serviço de saúde é a primeira relação de acolhimento do usuário. Quando os participantes deste estudo relataram suas experiências ao acessar o serviço de odontologia do módulo, eles apontaram pontos importantes desse primeiro momento do acolhimento (quadro 1). Szpilman, Oliveira ${ }^{15}$, afirmam que analisar o acesso é essencial na avaliação de um serviço, uma vez que é possível verificar a existência ou não de resolutividade, se funciona de maneira acolhedora para com o usuário, se promove a construção do vínculo e escuta.

Diante da temática "acolhimento" torna-se 
necessário analisar também a relação entre profissionais de saúde e usuários. Desde o início da década de 90 , as práticas dos profissionais de saúde eram identificadas como impessoais e fragmentadas, e isso se constituía como um dos grandes obstáculos para efetivação do SUS. Havia uma necessidade instalada de fazer reflexões que promovessem mudanças na organização dos serviços de saúde, e dentre estas a qualificação das relações entre usuários e profissionais de saúde ${ }^{1}$.

Nesse contexto, os relatos deste estudo evidenciaram a importância do diálogo entre as partes durante o atendimento, e ressaltaram o valor de ser tratado pelo "Nome" por profissionais e alunos.

"Tratava a minha filha pelo nome, ligava para ela e tudo mais!"

Sucupira ${ }^{16}$ enfatiza o quanto é importante os profissionais de saúde acolher os usuários, reconhecendo-os pelo nome, e depois interessando-se pelos aspectos subjetivos apresentados por eles, na vinda à unidade de saúde.

Pode-se afirmar que a qualificação das relações entre usuários e profissionais de saúde está se constituindo de maneira positiva no cenário de ensino-aprendizagem do curso de odontologia da UESB.

"Não tenho o que queixar. Me explicaram todo o procedimento[...] perguntam como estamos, conversam durante o tratamento[...] Com diálogo dá para construir uma relação entre nós e eles, e aqui eu vejo assim[...] Essa relação acaba melhorando o serviço."

Esmeraldo ${ }^{3}$ expressa claramente que não se pode pensar em acolhimento restringindo-se apenas na relação usuário e profissional, é preciso considerar tudo que permeia o processo de trabalho em saúde. Panizzi e Franco ${ }^{2}$, relatam que a escuta tenta resgatar, através de uma postura humanizada, a solidariedade e a relação de confiança atendendo de forma segura as necessidades daqueles que buscam os serviços de saúde. O trecho do depoimento a seguir traduz um pouco dessa relação:

"[...] explicou, falou o que ia fazer, e tudo e isso é bom porque passa mais confiança pra gente! Eu mesmo não gostava de dentista porque chegava lá e eles não falavam o que tava acontecendo, e aqui não, os alunos explicam tudo o que vai fazer. Isso aproxima o profissional do paciente".

O caminho para uma prática mais humanizada de atenção à saúde está sendo percorrido mesmo diante de algumas dificuldades. Dentre elas, foi identificada situação de constrangimento perante a forma como alguns professores conduzem as atividades e isso parece implicar na relação com o paciente, de maneira que coube aos alunos reformular essa ideia com o propósito de tranquilizar a paciente, como visto na fala abaixo:

"Assim né, as meninas foram excelentes[...] fizeram um trabalho maravilhoso, mas teve um professor que me deixou meio que com medo de voltar aqui outra vez[...] porém as meninas me explicaram tudo, e isso me deixou mais tranquila, apesar delas estarem começando..."

Em contrapartida, houve relato de uma situação onde a relação professor/aluno no processo de ensino/aprendizagem foi tão bem estabelecida que o paciente acabou por sentir-se mais seguro durante a realização do procedimento odontológico, conforme aponta a fala abaixo:

"[...] a moça que fez minha extração sempre chamava o professor, aí ele dava orientação e ela prosseguia o atendimento até extrair. A forma que eles fazem eu achei bom, eles são muito educados."

Alguns autores denominam acolhimento como posição, ou seja, pressupõe uma atitude da 
equipe no comprometimento em receber, escutar e tratar de forma humanizada os usuários e suas necessidades, por meio de uma relação de mútuo interesse entre trabalhadores e usuários estruturados como "relação de ajuda"17,18. Nessa perspectiva, também deve ser a relação professor/aluno diante do usuário durante o atendimento odontológico, uma vez que a clínica-escola não é só um ambiente acadêmico de ensino/aprendizagem, é também um local onde são prestados serviços de saúde à população.

Os trechos dos depoimentos do quadro 2 reforçam a importância de incorporar às práticas em saúde elementos de acolhida que se traduzam em atitudes humanizadas, éticas e de solidariedade, ficando, muitas vezes, os parâmetros técnicos em segundo plano. Emerge cada vez mais a necessidade de resgatar o cuidado humano, de exercitar a escuta.

O acolhimento é uma proposta de se repensar e refazer nova prática em saúde, pautada nas relações e no ato de receber e ouvir, capazes de proporcionar respostas adequadas àqueles que procuram os serviços de saúde ${ }^{3}$. Szpilman, Oliveira $^{15}$, reiteram que o acolhimento deve ser visto como uma prática que potencializa a formação de vínculos entre usuários e trabalhadores de saúde, imprimindo uma postura capaz de acolher, escutar e pactuar respostas mais adequadas aos usuários, que impliquem em mudanças nas práticas de saúde e, portanto, no processo de trabalho.

A metodologia qualitativa desta pesquisa possibilitou uma rica análise sobre as interações desenroladas neste ambiente onde convive o ensino na área de saúde e o serviço de saúde. Neste cenário os personagens são os professores, os alunos de graduação, e os usuários do serviço de saúde.

Quando se tratou de analisar o serviço odontológico prestado na universidade sob a ótica do usuário, foi intrigante constatar que apesar de haver quase uma unanimidade de opiniões favoráveis, estas vieram acompanhadas de sugestões e críticas (Quadro 3).

Um dos problemas apontados foi a questão das interrupções e falta de continuidade do tratamento odontológico, conforme pode-se ler a seguir:

"[...] tem tratamento que começa e não tem sequência, aí tem pacientes que acaba até perdendo os dentes como já aconteceu várias vezes aqui [...] uma turma começa e passa para outra que não dá sequência [...] por exemplo, começa fazer o canal e não termina, aí coloca o curativo né, deixa para outra turma pegar e terminar, aí a pessoa (paciente) não consegue atendimento fácil e acaba perdendo o dente, tá me entendendo?!"

Quando o usuário é acolhido por uma unidade de saúde, e tem seu atendimento garantido, é conquistada uma importante etapa na adesão do tratamento e resolução dos problemas de saúde. Dessa forma, favorece a construção de uma relação de confiança e respeito para com o usuário que busca o atendimento ${ }^{19}$. Contudo a falta de resolutividade, e neste caso, a não continuidade do tratamento indica falhas no processo de trabalho que resulta em insatisfação do usuário.

Outra situação levantada foi em relação à demora em finalizar do tratamento odontológico, conforme aponta o depoimento a seguir:

"O que deveria mudar só é a demora, porque às vezes tem greve, outras vezes que eu não sei o motivo a gente vem e não pode ser atendida naquele dia, eи mesmo fiquei muito tempo, uns dois anos para ser encaixada para conseguir essa prótese e isso é um ponto negativo."

Fica evidente que às vezes a informação não é passada de forma adequada, configurando 
numa falha no processo de organização e acolhimento, pois segundo Coelho, Jorge, Araújo ${ }^{19}$, o acolhimento deve ser dialogado em qualquer momento do atendimento, ou seja, em qualquer encontro dessa rede de conversações que são os serviços, e com isso procurar medidas para sanar os problemas relatados pelos usuários. Os mesmos autores afirmam também que a troca de conhecimentos entre as partes pode proporcionar uma melhor acolhida na unidade de saúde, e que essa parceria pode acarretar em soluções para dificuldades encontradas.

\section{CONCLUSÃO}

O processo de acolhimento aos usuários do curso de Odontologia da UESB segue o caminho para uma prática mais humanizada de atenção à saúde, mas ainda existem pontos que merecem ser analisados e repensados por todo corpo docente e discente que atua neste cenário. A organização da "porta de entrada" do serviço de saúde bucal da clínica-escola foi uma das deficiências observadas, além da questão relativa à interrupção do tratamento e a pouca resolutividade, no que tange a necessidade inicial que fez o usuário buscar o atendimento odontológico.

Se por um lado os usuários demostraram, de modo geral, uma percepção positiva em relação ao atendimento na clínica-escola da universidade, por outro, foi possível verificar que os discursos revelaram insatisfações que não se constituíram em meras "reclamações", mas em críticas construtivas. Tais achados se enquadram em valorosas informações para embasar discussões em torno da necessidade de reformulação da dinâmica do acolhimento e da formação dos graduandos de Odontologia, considerando a importância da escuta, da postura humanizada, da resolutividade, e da relação de confiança para com as pessoas que buscam o serviço de saúde numa instituição pública de ensino superior.

\section{ABSTRACT \\ Welcoming reception of users this dentistry service of a public university}

The Southwest Bahia State University course of Dentistry develop clinical activities at the Dentistry Building, a teaching and learning place that offer dental care to the Jequié/BA population. This study aimed to analyze the host users of this service process in order to identify the user's gateway and perception on the service provided. It is essentially a qualitative study in which was used a semi-structured interview to 45 users. The results of the empirical material were divided into three focus area: Access to dental care, relationship with teachers and students during dental care, and review of dental services provided. Users considered have been welcomed, but pointed out difficulties at the beginning of the treatment. Regarding the relationship between the parties during service, users highlighted points that indicate the existence of a humanized practice of oral health care. The statements identified failures in the reception of users, which leads to reflections on the organization of the "gateway" and continued treatment until its resolution. These findings constitute valuable information to support discussions on the sector's operating dynamics and the training of dentistry undergraduate students in taking into account the importance of the process of reception.

Descriptors: Humanization of assistance, user, dental care

\section{REFERÊNCIAS}

1. Andrade EIG, Cotta RMM, Mitre SM. Avanços e desafios do acolhimento na operacionalização e qualificação do Sistema Único de Saúde na Atenção Primária: um resgate da produção bibliográfica do Brasil. Ciênc Saúde Coletiva. 2012; 17(8): 2071-85.

2. Panizzi M, Franco TB. A implantação do acolher Chapecó reorganizando o processo de trabalho. In: Franco, TB. et al. (Orgs.). Acolher Chapecó: uma experiência de 
mudança do modelo assistencial com base no processo de trabalho. São Paulo: Hucitec; 2004. p.79-110.

3. Esmeraldo GROV, Lúcia CO, Keylla MMS, Michael AMA, Carlos EEF, Érica MNV. Análise do acolhimento na estratégia de saúde da família sob a perspectiva do usuário. Rev APS. 2009;12(2):119-30.

4. Brasil. Ministério da Saúde. Secretaria de Atenção à Saúde. Acolhimento nas práticas de produção de saúde. Brasília: Ministério da Saúde; 2008.

5. Brasil. Ministério da saúde. Conselho Nacional de saúde. XII Conferência Nacional de Saúde. Brasília: Ministério da Saúde; 2004.

6. Pereira AD, Freitas HMB, Ferreira CLL1. Atentando para as singularidades humanas na atenção à saúde por meio do diálogo e acolhimento. Rev Gaúcha Enferm. 2010; 31(1):55-6.

7. Mota LQ, Santos TA, Magalhães DBL. Humanização no atendimento odontológico: Acolhimento da subjetividade dos pacientes atendidos por alunos de graduação nos campos de estágio. Rev Bras Ciênc Saúde. 2012;16(4):537-44.

8. Merhy EE, Onocko R. Agir em saúde: um desafio para o público. 2.ed. São Paulo: Hucitec; 2002.

9. BRASIL. Conselho Nacional de Saúde. Resolução no 466 de 12 de Dezembro de 2012. Brasília: Ministério da Saúde; 2012.

10. Minayo MCS. O desafio do conhecimento: pesquisa qualitativa em saúde. 6.ed. São Paulo: HUCITEC/Abrasco;1999.

11. Bardin L. Análise de conteúdo. Lisboa: Edições 70; 2011.

12. Menezes RA, Speroni AV. Os sentidos do acolhimento: um estudo sobre o acesso à atenção básica em saúde no Rio de Janeiro. Cad Saúde Coletiva. 2014;22(4):380-5.
13. Lopes GVDO, Menezes TMO, Miranda AC, Araújo KL, Guimarães ELP. Acolhimento: quando o usuário bate a porta. Rev Bras Enferm. 2014;67(1):104-10.

14. Neves M, Pretto AS, Ely HC. Percepções de usuários e trabalhadores de saúde sobre a implantação do acolhimento em uma unidade de saúde em Porto Alegre-RS, Brasil. Rev Odontol UNESP. 2013;42(5):364-71.

15. Szpilman ARM, Oliveira AE. A percepção de usuários sobre os serviços de odontologia em unidades de saúde de Vila Velha (ES), Brasil. Rev Esp Saúde. 2011;12(2):28-37.

16. Sucupira AC. O acolhimento como expressão do direito à saúde. In: Prefeitura Municipal de Fortaleza. Secretaria Municipal de Saúde. Fortaleza humaniza SUS. Fortaleza. 2005.

17. Silva JAG, Mascarenhas MTM. Avaliação da atenção básica em saúde sob a ótica da integralidade: aspectos conceituais e metodológicos. In: Pinheiro R, Mattos RA. (Orgs.). Cuidado: as fronteiras da integralidade. São Paulo: Hucitec/ ABRASCO; 2004. p. 241-257.

18. Camello SHH, Angerami ELS, Silva EM, Mishima SM. Acolhimento à clientela: estudo em unidades básicas de saúde no Município de Ribeirão Preto. Rev Latinoam Enferm. 2000;8(4):30-7.

19. Coelho MO, Jorge MSO, Araújo ME. O acesso por meio do acolhimento na atenção básica à saúde. Rev Baiana Saúde Públ. 2009;33(3):440-52.

Correspondência para:

Patrícia Elizabeth Souza Matos

e-mail: pesmatos@gmail.com

Universidade Estadual do Sudoeste da Bahia Departamento de Saúde I.

Av. José Moreira Sobrinho, s/n, Jequiezinho - Jequié/BA 